\title{
Assessment of resin-dentin interfacial morphology of two ethanol-based universal adhesives: A scanning electron microscopy study
}

\author{
Mohamed Moustafa Awad ${ }^{1}$
}

Correspondence: Dr. Mohamed Moustafa Awad

Email:dr.mm.awad@hotmail.com

\begin{abstract}
'Department of Conservative Dental Sciences, College of Dentistry, Prince Sattam Bin Abdulaziz University, Al-Kharj, Riyadh, KSA
\end{abstract}

\section{ABSTRACT}

Objective: The objective of this study was to assess the resin-dentin interfacial morphology created by two universal adhesives using scanning electron microscopy (SEM). Materials and Methods: The occlusal surfaces of ten $(n=5)$ molars were reduced to expose a flat surface of dentin. Two universal adhesives, Scotchbond Universal Adhesive and Tetric N-Bond Universal, were independently applied to air-dried dentin. Light-cured resin-based composite restorative materials were used to incrementally build a composite "buildup." The specimen was sectioned mesiodistally to expose the resin-dentin interface. The inner surfaces of the specimens were polished. Samples were immersed in hydrochloric acid and then rinsed using distilled water. This was followed by immersion of the samples in $1 \%$ sodium hypochlorite solution. Then, samples were thoroughly rinsing with distilled water. Dehydration of samples was performed using ascending concentration of ethyl alcohol. Prepared samples were observed SEM at magnifications $\times 1500$ and $x 4000$. Results: Both universal adhesives could penetrate dentin-forming well-defined resin tags, lateral branches as well as a uniform hybrid layer. Conclusions: Two tested universal adhesives applied in self-etch mode can infiltrate into dentin-producing high-quality interfacial morphology. Similar interfacial morphology may be due to the similarity in composition and application mode.

Key words: Adhesive, hybrid layer, resin tags

\section{INTRODUCTION}

Current dental adhesive systems are categorized into two main classes on the basis of the technique of bonding to dental substrates: the etch-and-rinse adhesives that require the application of an acid etchant to the dental substrate before use and the self-etch adhesives (SEAs) for which the use of acid etchant is not mandatory. ${ }^{[1,2]}$

SEAs can either be two-step adhesives in which the application of an acidic primer is followed by

\begin{tabular}{|l|l|}
\hline \multicolumn{2}{|c|}{ Access this article online } \\
\hline Quick Response Code: \\
\hline
\end{tabular}

that of a hydrophobic bonding agent, or one-step adhesives. The one-step SEAs can be further subdivided into two types: two-component adhesives that require mixing before use and single-component adhesives. $^{[1]}$ Thus, the single-component, one-step SEAs are considered as "all-in-one" adhesives, as they combine "conditioning," "priming," and "application of the bonding agent," and require no mixing. ${ }^{[1]}$ Low technique sensitivity, ease of use, and simplicity

This is an open access article distributed under the terms of the Creative Commons Attribution-NonCommercial-ShareAlike 3.0 License, which allows others to remix, tweak, and build upon the work non-commercially, as long as the author is credited and the new creations are licensed under the identical terms.

For reprints contact: reprints@medknow.com

How to cite this article: Awad MM. Assessment of resin-dentin interfacial morphology of two ethanol-based universal adhesives: A scanning electron microscopy study. Eur J Dent 2017;11:206-9.

DOI: 10.4103/ejd.ejd_244_16 
have caused SEAs to be widely used in restorative practice. ${ }^{[3,4]}$

Based on micromechanical adhesion mechanism, ${ }^{[5]}$ a strong bonding between adhesives and dental substrates may depend on the ability of adhesive monomers to penetrate the dental substrates. ${ }^{[6]}$ The self-etch bonding strategy involves the penetration of acidic monomers beyond the smear layer into mineralized dentin by partially dissolving hydroxyapatite to generate a resin-infiltrated zone with minerals incorporated. ${ }^{[7]}$ However, if SEAs are not able to penetrate to demineralize the dentin to form a hybridized zone, their bonding performance may be negatively affected. ${ }^{[8]}$ Universal or multimode adhesives may represent the latest generation of dental adhesives. ${ }^{[9-11]}$ Universal adhesives are designed to bond to tooth structures through the etch-and-rinse or the self-etch bonding strategies, using the same adhesive. ${ }^{[10]}$ Despite their versatility, universal adhesives are primarily SEAs. ${ }^{[12]}$ Several universal adhesives are currently available. However, detailed information on their ability to penetrate or interact with the dental tissues may be required. Therefore, the purpose of this in vitro investigation was to assess the resin-dentin interfacial morphological characteristics of two ethanol-based universal adhesives, namely, Scotchbond Universal Adhesive (SBU) and Tetric N-Bond Universal (TNU) using scanning electron microscopy (SEM).

\section{MATERIALS AND METHODS}

\section{Specimen preparation}

Ten permanent human third molars, extracted for surgical reasons, were used after approval from the Local Ethics Committee. The occlusal surfaces of molars were reduced using a diamond saw under water cooling, to expose a flat surface of mid-coronal dentin. The dentin surfaces were inspected using a magnifying loop to ensure that there were no remnants of enamel. Then, they were polished with \# 600 grit silicon carbide paper under running water and were subjected to ultrasonic cleaning for $10 \mathrm{~min}$.

The two universal adhesives, SBU and TNU, were applied, separately, to the air-dried dentin surfaces [Table 1] with scrubbing motion, using micro brushes, for $20 \mathrm{~s}$. These were light cured for $10 \mathrm{~s}$, using a light-emitting diode (LED) light-curing unit (SmartLite Max LED Curing Light, Dentsply Caulk) operated at $900 \mathrm{~mW} / \mathrm{cm}^{2}$. Immediately after light curing of adhesives, the resin-based composite Tetric N-ceram was used to incrementally build a composite "buildup" that was 3-4 mm in height, with peripheral borders maintained entirely in the dentin. Each increment (approximately $1 \mathrm{~mm}$ ) was light cured for $20 \mathrm{~s}$ from approximately $1 \mathrm{~mm}$. After composite buildup, each specimen was sectioned mesiodistally to expose the resin-dentin interface.

\section{Specimen preparation for scanning electron microscopy examination}

The inner surfaces of specimens were polished using polishing discs (Flexi-D EVE Ernst Vetter GmbH) with a speed of $5000 \mathrm{rpm}$ under water cooling. Samples were immersed in $6 \mathrm{~mol} / \mathrm{L}$ hydrochloric acid for $30 \mathrm{~s}$ to remove minerals within the hybrid layer that was not protected by resin infiltration. The specimens were rinsed, using distilled water, for $1 \mathrm{~min}$. This was followed by immersion of the specimens in $1 \%$ sodium hypochlorite solution for $10 \mathrm{~min}$ to dissolve all exposed collagen beneath the hybrid layer. Then, the specimens were thoroughly rinsed with distilled water for $5 \mathrm{~min}$. Dehydration of the specimens was performed using ascending concentrations of ethyl alcohol (25\% for $20 \mathrm{~min}, 50 \%$ for $20 \mathrm{~min}, 75 \%$ for $20 \mathrm{~min}, 95 \%$ for $30 \mathrm{~min}$, and $100 \%$ for $60 \mathrm{~min}) .{ }^{[13]}$ The samples thus prepared

\begin{tabular}{|c|c|c|}
\hline Material/manufacturer & Composition & Manufacturer's instructions \\
\hline $\begin{array}{l}\text { SBU } \\
\text { 3M ESPE, St. } \\
\text { Paul, MN, USA }\end{array}$ & $\begin{array}{l}\text { MDP, dimethacrylate, HEMA, vitrebond copolymer, } \\
\text { filler, ethanol, water, initiators, and silane }\end{array}$ & $\begin{array}{l}\text { Apply one drop agitate for } 20 \mathrm{~s} \\
\text { Gently air dry for } 5 \mathrm{~s} \\
\text { Photopolymerize for } 20 \mathrm{~s}\end{array}$ \\
\hline $\begin{array}{l}\text { TNU } \\
\text { Ivoclar Vivadent; } \\
\text { Schaan, Liechtenstein }\end{array}$ & $\begin{array}{l}\text { MDP, MCAP, HEMA, D3MA water, ethanol, highly } \\
\text { dispersed silicon dioxide, initiators, and stabilizers }\end{array}$ & $\begin{array}{l}\text { Scrub for at least } 20 \mathrm{~s} \\
\text { Disperse with oil- and moisture-free compressed } \\
\text { air until a glossy, immobile film layer } \\
\text { Light cure for } 10 \mathrm{~s}\end{array}$ \\
\hline $\begin{array}{l}\text { Tetric N-Ceram } \\
\text { Ivoclar Vivadent; } \\
\text { Schaan, Liechtenstein }\end{array}$ & $\begin{array}{l}\text { Urethane dimethacrylate, Bis-GMA, ethoxylated Bis-EMA, } \\
\text { triethylene glycol dimethacrylate, barium glass, ytterbium } \\
\text { trifluoride, mixed oxide, silicon dioxide, prepolymers, } \\
\text { additives, stabilizers, catalysts, and pigments }\end{array}$ & \\
\hline
\end{tabular}


were observed with SEM (QUANTA FEG 250, FEI Company, The Netherlands) at magnifications $\times 1500$ and $\times 4000$.

\section{RESULTS}

SEM examinations (magnifications $\times 1500$ and $\times 4000$ ) of the resin-dentin interfaces created by the two universal adhesives showed similar interfacial morphological features [Figures 1 and 2]. SBU and TNU could penetrate the dentin-forming well-defined resin tags, lateral branches, and a uniform hybrid layer. Resin tags produced by the SBU showed anastomosis feature. The resin tags created by TNU were relatively shallower but more uniform compared to those of SBU. Predominant features of the two adhesive-dentin interfaces are listed in Table 2.

\section{DISCUSSION}

The ability of the adhesive systems to infiltrate into dental substrates and form high-quality hybridization is one of the requirements for adequate bonding. ${ }^{[14-16]}$ Although interpretation of resin tag formation is controversial, ${ }^{[17]}$ the morphology, length, and density of resin tags are used for evaluation of the efficiency of adhesive systems. ${ }^{[18,19]}$

\begin{tabular}{|c|c|c|c|}
\hline \multirow[t]{2}{*}{ Adhesive } & \multicolumn{3}{|c|}{ Feature } \\
\hline & Resin tag formation & Lateral branches & Hybrid layer \\
\hline SBU & $\begin{array}{l}\text { Present } \\
\text { Not uniform } \\
\text { Deeper } \\
\text { Anastomosed }\end{array}$ & Present & Uniform \\
\hline TNU & $\begin{array}{l}\text { Present } \\
\text { Uniform } \\
\text { Shallower } \\
\text { Dense }\end{array}$ & Present & Uniform \\
\hline
\end{tabular}

SBU: Scotchbond Universal Adhesive, TNU: Tetric N-Bond Universal

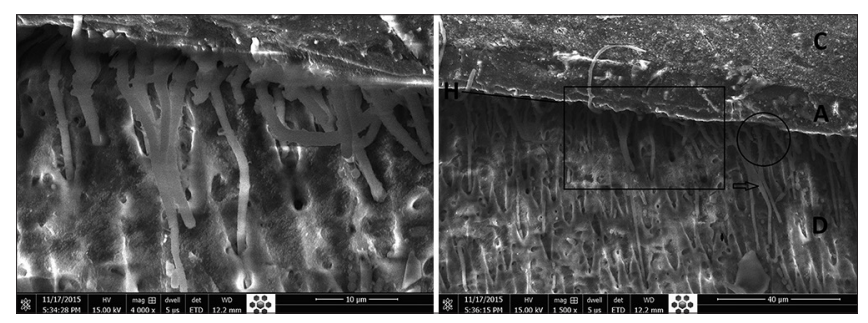

Figure 1: Scanning electron microscopy micrograph of the resin-dentin interface created by the Scotchbond Universal Adhesive. C: Composite, A: Adhesive, D: Dentin, H: Hybrid layer, Arrow: Resin tags (anastomosed), Rectangle: Section shown at magnification $\times 4000$. Rounded: Lateral branches $(\times 1500$ [right side] and $\times 4000$ [left side])
Despite significant improvements in adhesive systems, the resin-tooth interface remains the weakest area of composite resin restorations. ${ }^{[20]}$ In this study, theinterfacial morphological characteristics of two ethanol-based universal adhesives, used in the self-etch mode, were evaluated using SEM. Both universal adhesives could penetrate the dentin-forming well-defined resin tags and lateral branches. Universal or multimode adhesives are primarily SEAs. ${ }^{[12]}$ Both tested adhesives are one-step SEAs; SEAs demineralize and infiltrate the tooth structure simultaneously. ${ }^{[1]}$ During substrate penetration, the acidic monomers of adhesives are gradually buffered by the mineral content of the substrate, losing their ability to further etch dentin. ${ }^{[8,21]}$ The bonding ability of one-step SEAs depends on their specific composition. SEAs consist of resin monomers with functional groups, hydrophilic monomers, hydrophobic monomers, solvents, fillers, and initiators. ${ }^{[22,23]}$ Interfacial morphology of both adhesives may also be affected by similarity of their compositions. Both tested adhesives were water-containing, ethanol-based, and hydroxyethyl methacrylate (HEMA)-containing adhesives. Water is essential to ionize the acidic monomers and trigger the demineralization process. ${ }^{[24]}$ However, due to the low vapor pressure of water, it is usually combined with organic solvents of higher vapor pressure, in the adhesives, to ensure its evaporation. ${ }^{[24]}$ Water-ethanol combination in both adhesives may also help to dilute the viscous monomers and facilitate its infiltration into dentin. ${ }^{[25]}$

HEMA is a conventional hydrophilic methacrylate monomer, incorporated into dental adhesive compositions ${ }^{[24]}$ due to its hydrophilicity, which makes it an excellent adhesion promoter. ${ }^{[5]}$ HEMA may enhance wetting properties and dentin penetration efficacy of adhesives. ${ }^{[26-28]}$ The presence of HEMA in both adhesives plays a key role in their similar interfacial morphology. The tooth interfacial morphological feature of SEAs may depend on their $\mathrm{pH} .{ }^{\left[{ }^{[29]}\right.}$ Based on their aggressiveness or acidity, SEA can be classified
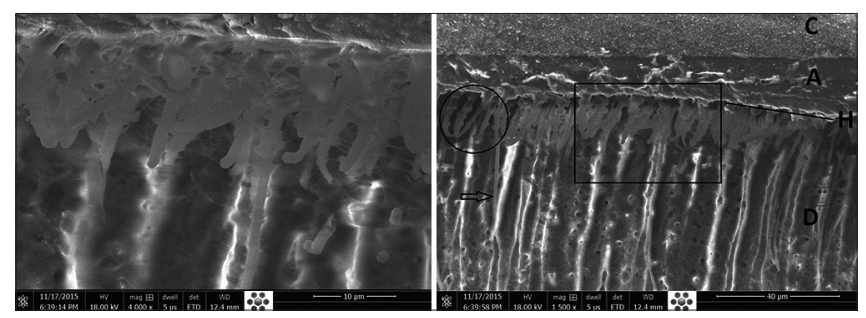

Figure 2: Scanning electron microscopy micrograph of the resin-dentin interface created by the Tetric N-Bond Universal. C: Composite, A: Adhesive, D: Dentin, H: Hybrid layer Arrow: Resin tag, Rectangle: Section shown at magnification $\times 4000$. Rounded: Lateral branches $(\times 1500$ [right side] and $\times 4000$ [left side] $)$ 
into strong $(\mathrm{pH} \leq 1)$, intermediately strong $(\mathrm{pH} 1-2)$, mild $(\mathrm{pH} \approx 2)$, or ultra-mild $(\mathrm{pH}>2.5) \cdot{ }^{[1,25]}$ In this study, SBU and TNU have $\mathrm{pH}$ of 2.7 and 2.5-3.0, respectively. Thus, the two tested adhesives can be mild or ultra-mild SEAs. This may also explain the similar interfacial morphology created by both adhesives.

In addition to the compositional factors, the application mode may also have influenced the interfacial morphology of adhesives. As recommended by manufacturers of the adhesives, scrubbing or vigorous application was performed for $20 \mathrm{~s}$. It is believed that active application of adhesive improves infiltration of resin monomers into the dental substrates. ${ }^{[7,30,31]}$ Active agitation is essential for SEAs as it may assist smear layer removal and improve the contact of the acidic monomers with the tooth surface. ${ }^{[31]}$ In contrast, the interfacial morphological differences may be attributed to the differences in the resin content of the two universal adhesives. However, further investigations may be required to confirm this speculation.

\section{CONCLUSIONS}

The two tested universal adhesives, applied in self-etch mode, can infiltrate into dentin-producing high-quality interfacial morphology. The similar interfacial morphology may be due to similarity in composition and application protocol.

\section{Financial support and sponsorship}

Nil.

\section{Conflicts of interest}

There are no conflicts of interest.

\section{REFERENCES}

1. Van Meerbeek B, Yoshihara K, Yoshida Y, Mine A, De Munck J, Van Landuyt KL. State of the art of self-etch adhesives. Dent Mater 2011;27:17-28.

2. Pashley DH, Tay FR, Breschi L, Tjäderhane L, Carvalho RM, Carrilho M, et al. State of the art etch-and-rinse adhesives. Dent Mater 2011;27:1-16.

3. Inoue S, Vargas MA, Abe Y, Yoshida Y, Lambrechts P, Vanherle G, et al. Microtensile bond strength of eleven contemporary adhesives to enamel. Am J Dent 2003;16:329-34.

4. Van Meerbeek B, Kanumilli P, De Munck J, Van Landuyt K, Lambrechts P, Peumans M. A randomized controlled study evaluating the effectiveness of a two-step self-etch adhesive with and without selective phosphoric-acid etching of enamel. Dent Mater 2005;21:375-83.

5. Van Meerbeek B, De Munck J, Yoshida Y, Inoue S, Vargas M, Vijay P, et al. Buonocore memorial lecture. Adhesion to enamel and dentin: Current status and future challenges. Oper Dent 2003;28:215-35.

6. Zhang Y, Wang Y. Effect of application mode on interfacial morphology and chemistry between dentine and self-etch adhesives. J Dent 2013;41:231-40.

7. do Amaral RC, Stanislawczuk R, Zander-Grande C, Gagler D, Reis A, Loguercio AD. Bond strength and quality of the hybrid layer of one-step self-etch adhesives applied with agitation on dentin. Oper Dent 2010;35:211-9.

8. Carvalho RM, Chersoni S, Frankenberger R, Pashley DH, Prati C, Tay FR. A challenge to the conventional wisdom that simultaneous etching and resin infiltration always occurs in self-etch adhesives. Biomaterials 2005;26:1035-42.

9. de Goes MF, Shinohara MS, Freitas MS. Performance of a new one-step multi-mode adhesive on etched vs. non-etched enamel on bond strength and interfacial morphology. J Adhes Dent 2014;16:243-50.

10. Hanabusa M, Mine A, Kuboki T, Momoi Y, Van EndeA, Van Meerbeek B, et al. Bonding effectiveness of a new 'multi-mode' adhesive to enamel and dentine. J Dent 2012;40:475-84.

11. Muñoz MA, Sezinando A, Luque-Martinez I, Szesz AL, Reis A Loguercio AD, et al. Influence of a hydrophobic resin coating on the bonding efficacy of three universal adhesives. J Dent 2014;42:595-602.

12. Wagner A, Wendler M, Petschelt A, Belli R, Lohbauer U. Bonding performance of universal adhesives in different etching modes. J Dent 2014;42:800-7.

13. Nagpal R, Manuja N, Tyagi SP, Singh UP. In vitro bonding effectiveness of self-etch adhesives with different application techniques: A microleakage and scanning electron microscopic study. J Conserv Dent 2011;14:258-63.

14. Gwinnett AJ, Tay FR, Pang KM, Wei SH. Quantitative contribution of the collagen network in dentin hybridization. Am J Dent 1996;9:140-4

15. Nakabayashi N, Kojima K, Masuhara E. The promotion of adhesion by the infiltration of monomers into tooth substrates. J Biomed Mater Res 1982;16:265-73.

16. Salvio LA, Hipólito VD, Martins AL, de Goes MF. Hybridization quality and bond strength of adhesive systems according to interaction with dentin. Eur J Dent 2013;7:315-26.

17. Langer A, Ilie N. Dentin infiltration ability of different classes of adhesive systems. Clin Oral Investig 2013;17:205-16.

18. Giachetti L, Bertini F, Scaminaci Russo D. Investigation into the nature of dentin resin tags: A scanning electron microscopic morphological analysis of demineralized bonded dentin. J Prosthet Dent 2004;92:233-8.

19. Dagostin A, Ferrari M. In vivo bonding mechanism of an experimental dual-cure enamel-dentin bonding system. Am J Dent 2001;14:105-8.

20. Ayar MK. A review of ethanol wet-bonding: Principles and techniques. Eur J Dent 2016;10:155-9.

21. Salz U, Mücke A, Zimmermann J, Tay FR, Pashley DH. pKa value and buffering capacity of acidic monomers commonly used in self-etching primers. J Adhes Dent 2006;8:143-50.

22. Vanajasan PP, Dhakshinamoorthy M, Rao CS. Factors affecting the bond strength of self-etch adhesives: A meta-analysis of literature. J Conserv Dent 2011;14:62-7.

23. Finger WJ, Shao B, Hoffmann M, Kanehira M, Endo T, Komatsu M. Does application of phase-separated self-etching adhesives affect bond strength? J Adhes Dent 2007;9:169-73.

24. Van Landuyt KL, Snauwaert J, De Munck J, Peumans M, Yoshida Y, Poitevin A, et al. Systematic review of the chemical composition of contemporary dental adhesives. Biomaterials 2007;28:3757-85.

25. Wang Y, Spencer P, Yao X, Brenda B. Effect of solvent content on resin hybridization in wet dentin bonding. J Biomed Mater Res A 2007;82:975-83

26. Toledano M, Osorio R, Moreira MA, Cabrerizo-Vilchez MA, Gea P, Tay FR, et al. Effect of the hydration status of the smear layer on the wettability and bond strength of a self-etching primer to dentin. Am J Dent 2004;17:310-4.

27. Zanchi $\mathrm{CH}$, Münchow EA, Ogliari FA, de Carvalho RV, Chersoni S, Prati C, et al. Effects of long-term water storage on the microtensile bond strength of five experimental self-etching adhesives based on surfactants rather than HEMA. Clin Oral Investig 2013;17:833-9.

28. Van Landuyt KL, Snauwaert J, Peumans M, De Munck J, Lambrechts P, Van Meerbeek B. The role of HEMA in one-step self-etch adhesives. Dent Mater 2008;24:1412-9.

29. Koshiro K, Sidhu SK, Inoue S, Ikeda T, Sano H. New concept of resin-dentin interfacial adhesion: The nanointeraction zone. J Biomed Mater Res B Appl Biomater 2006;77:401-8.

30. Chan KM, Tay FR, King NM, Imazato S, Pashley DH. Bonding of mild self-etching primers/adhesives to dentin with thick smear layers. Am J Dent 2003;16:340-6.

31. do Amaral RC, Stanislawczuk R, Zander-Grande C, Michel MD, Reis A, Loguercio AD. Active application improves the bonding performance of self-etch adhesives to dentin. J Dent 2009;37:82-90. 